\title{
O Desafio da Comunicação nos Museus Universitários
}

\section{The communication challenge in university museums}

\author{
Letícia Julião' \\ DOI 10.265I2/museologia.v9iEspecial.32082
}

\section{Resumo}

Novas formas de conceber a comunicação desafiam os museus universitários a romper com o modelo hierárquico, que pressupõe uma carência de informação do visitante, em favor de uma comunicação multireferenciada, na qual novos atores e narrativas emergem na cena museal. $\bigcirc$ artigo analisa a natureza do colecionamento no âmbito das universidades, a musealização e as modalidades de comunicação desse patrimônio, e as alternativas que sublinham para a democratização das relações dos museus com o público: a exposição de controvérsias e da dinâmica de produção de conhecimento, compreendendo processos colaborativos e de negociação, e o uso tecnologias da informação como ferramenta para ampliar audiências e a formação de redes de pesquisadores e acervos.

\section{Palavras-chave}

Museus universitários. Comunicação museológica. Comunicação democrática. Exposição e conhecimento.

\begin{abstract}
New ways of conceiving communication challenge university museums to break with the hierarchical model, which presupposes a lack of information from the visitor, in favor of multi-referenced communication, in which new actors and narratives emerge in the museum scene. The article analyzes the nature of collection within universities, the musealisation and the communication modalities of this heritage, and the alternatives that emphasize the democratization of museums' relations with the public: the exhibitions of controversies and the dynamics of knowledge production, include collaborative and negotiation processes, and the use of information technologies as a tool to expand audiences and the formation of networks of researchers and collections.
\end{abstract}

\section{Keywords}

University museums. Museological communication. Democratic communication. Exhibition and knowledge.

\section{Introdução}

No cenário museológico brasileiro, os museus universitários ocupam um lugar que, com raras exceções, ainda está por ser devidamente reconhecido tanto do ponto de vista acadêmico quanto das políticas públicas para a área. De aproximadamente 3.700 instituições constantes no Cadastro Nacional de Museus, algo em torno de 400 caracterizam-se como museus universitários. Mais de $10 \%$ dessas instituições, portanto, são geridas por universidades que tutelam, certamente, um dos mais importantes e expressivos patrimônios museológicos do país.

É certo que o número de espaços com interface museal nas universidades ultrapassa o total apresentado no Cadastro Nacional de Museu. Mas o dado por si só já é indicativo do papel desempenhado pelas universidades como polos de colecionamento. Centros de produção de conhecimento e ensino, essas

I Doutora em História (2008), mestre em Ciência Política (1992) e bacharel e licenciada em História (198I e 1983) pela UFMG. Professora Associada, UFMG. Atua no Curso de Museologia/Escola de Ciência da Informação e nos Programas de Pós Graduação em Ciência da Informação e Promestre - UFMG; e Museologia e Patrimônio - UFRGS. E-mail: juliao.leticia@gmail.com 
instituições constituíram-se historicamente em lugares de reunião de evidências materiais de realidades que se quer conhecer. Como assinala Latour (2008), as coleções funcionam como inscrições que fazem a mediação entre a realidade ausente, objeto do conhecimento, e o lugar que conhece. Muitos acervos universitários se formam, por conseguinte, a partir de operações próprias da metodologia de produção do conhecimento. Espécie de artifício de aproximação, as coleções reúnem e conferem universalidade ao que está disperso, ao que é singular no mundo, funcionando como dispositivos que reduzem ou amplificam realidades, permitindo, dessa maneira, procedimentos próprios da pesquisa como a observação, a comparação, a mensuração, classificação e interpretação. Algumas coleções são constituídas com propósito exclusivo de ensino, e se prestam para ilustrar conteúdos; outras transitam dos laboratórios de pesquisa para as salas de aulas. Como apoio didático, são portadoras de informações que nutrem o conhecimento científico e emprestam materialidade a ideias abstratas ou a processos experimentais no exercício da docência.

Como centro de poder e prestígio, a universidade também é destinatária de acervos constituídos fora do âmbito acadêmico. Coleções de arte, acervos particulares de intelectuais, pesquisadores, políticos ou de entidades de projeção pública são incorporados à universidade, em geral em processos de doação, tornando-se fontes e objeto de pesquisa e ensino. (Julião, 20I5).

Outra categoria de acervo são os artefatos que cercam o cotidiano da vida universitária, compreendendo desde o mobiliário e o patrimônio edificado que conformam os ambientes acadêmicos até os objetos científicos. Nessa tipologia importa destacar os instrumentos científicos, máquinas, utensílios ${ }^{2}$ que dão suporte e viabilizam processos de produção e disseminação do conhecimento, prestando-se à observação e ao reconhecimento sensível de realidades; à demonstração ou à simulação de fenômenos, teorias ou leis. São objetos que ao perderem a vida útil em razão de novas tecnologias ou por estarem associados a práticas científicas em desuso ingressam em uma zona imprecisa entre o descarte e a salvaguarda. Diferentemente das coleções constituídas em processos investigativos ou pedagógicos, requerem, portanto, um exercício permanente de reconhecimento de seu valor como patrimônio científico. (Segantini; Julião, 2017).

Para além de identificar as coleções pelas práticas que originalmente ensejam sua incorporação à universidade - ensino, pesquisa, políticas simbólicas, operacionalização das atividades acadêmicas - é preciso reconhecer, sobretudo, a pluralidade notável desses acervos. Eles documentam a cultura científica, intelectual e acadêmica, e podem ter natureza tão diversa quanto é a amplitude do saber e fazer humano. Comportam, por conseguinte, valores e significados que ultrapassam o interesse de comunidades universitárias específicas. São acervos que figuram como referências culturais da sociedade, constituem-se em recursos para o desenvolvimento humano e integram o que se pode identificar como patrimônio científico mundial.

O reconhecimento da dimensão social do patrimônio universitário está na origem de sua musealização. $O$ termo, convém esclarecer seu sentido, diz respeito ao processo no qual objetos são deslocados de seu contexto original,

2 A respeito da categorização dos objetos científicos ver LOURENÇO, Marta e GRANATO, Marcus. Thesaurus de Acervos Científicos em Língua Portuguesa. Museu Nacional de História Natural e da Ciência (Universidade de Lisboa) e pelo Museu de Astronomia e Ciências Afins do Rio de Janeiro (MAST). Disponível em http://thesaurusonline.museus.ul.pt/default.aspx 
convertidos em signos e testemunhos da realidade e inseridos em contextos museológicos. É processo que produz a musealidade - valor socialmente atribuído ao objeto como documento de determinada realidade, em contexto distinto de seu contexto primário. Ou como formulado por Zbynek Stránsky: “c'est une valeur spécifique, désignée comme la 'musealité' des objets qui est recherchée et qui amène l'être humain à les préserver, les étudier et les présenter"3. ( Desvallées, Mairesse, 20I I: 256)

Efetivamente, a musealização implica em uma cadeia de ações concernentes à preservação, pesquisa e comunicação, em estabelecimento de um cenário museal, que se distingue de outras atividades do colecionismo. No transcurso dessas ações, ocorre sempre a patrimonialização, lembra Mairesse, mas o inverso não é verdadeiro:

\begin{abstract}
La patrimonialisation participe du processos de muséalisation, mais ne l'englobe pas totalmente: tout de qui est muséalisé est patrimonialisé, mas tout ce qui est patrimonialisé n'est pas muséalisé et le reflexe patrimonial ( sauver ce que nous considérons comme du patrimoine des riques de la destruction) diffère du réflee museal ( connaitre et transmetre). (Mairesse, 201 I: 254)
\end{abstract}

A distinção entre um processo e outro está na perspectiva comunicacional da musealização. Vale notar que a patrimonialização envolve também algum grau de comunicação. Proteger o que se considera digno de ficar para a posteridade significa assegurar a sua transmissão às gerações futuras. A própria palavra patrimônio, do latim patrimonium, remete para a esfera do jurídico, associando-se à ideia de propriedade, tanto no sentido de possessão, quanto de transmissão. É possível dizer que tanto o objeto musealizado quanto o patrimonializado são salvaguardados para assegurar sua transmissão, mas o primeiro encontra-se distintivamente em contexto pontecializado de comunicação, implicando em processos complexos que ultrapassam o transporte de uma informação de um lugar a outro, de um tempo a outro. A própria transmissibilidade, que introduz os objetos em novos contextos, é condição que lhes confere novos valores, ou seja: "Quando uma coisa é transmitida ela é invariavelmente alterada, em certa medida, e jamais voltará a ser o que era antes” (Brulon, 2016: 47). No desdobramento das ações de musealização, assinala Brulon, são operadas alterações no valor do objeto para que ele possa fazer parte da realidade museal.

Nessa cadeia da musealização, a comunicação museológica figura certamente como o grande desafio para os museus ou instituições com interface museológica nas universidades. Como estabelecer uma comunicação para uma audiência ampliada, equilibrando-a com as demandas específicas de pesquisa e de ensino, próprias do cotidiano universitário? Que diferencial podem os museus universitários oferecer ao público?

3 "É um valor específico, designado como musealidade dos objetos, que é buscado pelo ser humano e que - leva a preservá-los, estudá-los e apresentá-los” (tradução nossa).

4 "A patrimonialização participa do processo de musealização, mas não a engloba totalmente: tudo que é musealizado é patrimonializado, mas nem tudo que é patrimonializado é musealizado, e o reflexo patrimonial (salvar dos riscos da destruição o que consideramos como patrimônio) difere do reflexo museal (conhecer e transmitir)" (tradução nossa). 


\section{Alguns caminhos da comunicação em exposições}

Desde as últimas décadas do século $X X$, os museus experimentam mudanças substantivas, tensionados pelas demandas de ampliação da sua audiência e de ressignificação de sua função social. Nesse processo, surgem novas tipologias de museus e novos delineamentos da noção de patrimônio museológico e das narrativas expositivas. Os museus universitários, por certo, não estão dissociados desse processo. $O$ público e o compartilhamento de patrimônio universitário têm sido colocados no centro de suas atenções, impelindo-os a renovar linguagens e conteúdos, e a experimentar relações mais horizontalizadas com o publico, nos seus processos comunicacionais.

As universidades foram lugares protagonistas no processo de configuração dos museus na modernidade. Como o exemplo clássico do Museu Ashmolen, surgido no século XVII, na Universidade de Oxford, Inglaterra, muitos outros lhe sucederam no mundo, com a missão de formar e preservar coleções para o uso científico e acadêmico. Da coleta à forma de mostrar as coleções, os museus universitários, mas não apenas eles, concorreram e ainda concorrem, para dar suporte às operações implicadas no desenvolvimento dos saberes disciplinares. Nota-se que em alguns casos foram decisivos para a emergência e conformação de novas disciplinas. Funcionavam como teatro da produção da ciência, onde as coleções - veículos de inscrições da realidade - permitiam aos eruditos e cientistas exercerem o domínio intelectual sobre fatos e fenômenos a serem interpretados. Apresentavam-se como panóticos do saber, como sugerem Rasse e Girault (20I I), ao se referirem especialmente aos museus de história natural no século XIX. A imagem do panótico é sugestiva do quanto essas instituições permitiram organizar e visualizar as coleções, de acordo com uma coerência que seguia classificações e sistemáticas científicas, ao mesmo tempo em que asseguravam publicidade ao conhecimento.

Ainda que estivessem abertos à visitação pública, os museus eram concebidos por homens de ciência, e se destinavam, sobretudo, a nutrir suas ideias científicas e apenas eventualmente se dedicavam à educação do público (Rasse; Girault, 20ll). As exposições externavam, por conseguinte, relações hierarquizadas, tecidas nas imbricações entre o poder e o saber. Estavam fundamentadas na centralidade do objeto, na lógica taxonômica, e sua legibilidade pressupunha uma audiência seleta, familiarizada com os saberes da ciência.

Esse tipo de exposição identifica-se com a Museologia do objeto, herdeira da concepção enciclopédica, modelo ao qual se somam dois outros, de acordo com Davallon (2010 e 20I I), correspondentes à Museologia de ideia ou do saber e à Museologia do ponto de vista. Se no primeiro modelo, a exposição, em geral, se estrutura em unidades compostas pelo objeto e sua etiqueta, na Museologia de ideia ou saber, as unidades estão articuladas entre si, e são introduzidos vários recursos - textos, vídeos, ilustrações - com o objetivo de promover a legibilidade da exposição.

Embora os modelos apresentados por Davallon não se sucedam linearmente no tempo, e nem mesmo mantenham fronteiras muito claras entre si, é possível associar o padrão expositivo da Museologia de ideia ao que Shiele (1992) analisa como a emergência da narrativa em exposições, no período entre Guerras nos EUA. As exposições universais de Chicago (1933-1934) e, mais tarde, de Nova York (1939-1940), segundo o autor, se anteciparam aos museus ao se estruturarem para articular objetos a uma determinada mensagem. Ainda 
que o objeto não tenha saído de cena, a narrativa, como forma de conectar uma história, passaria a figurar, nos museus, como recurso privilegiado para se transmitir uma mensagem ao público. Nos anos que se seguem ao fim da Segunda Guerra Mundial, essa modalidade expositiva, na qual é reservada ao visitante a posição central na recepção de informação, consolidou-se por meio do incremento de exposições temporárias e itinerantes. Do objeto à ideia, os museus passam a ser percebidos como meio de comunicação e meio educativo; se preocupam, portanto, com a eficácia de suas exposições e com processos de aprendizagem, desenvolvidos em relações mais complexas de comunicação com o seu público. (Shiele, 1992).

Numa analogia aos modelos de museus analisados por Padró (2003), é possível identificar que na exposição centrada no objeto prevalece o entendimento de que todos visitantes têm o mesmo conhecimento do especialista ou curador e aprendem do mesmo modo, enquanto na exposição de ideia, o museu é concebido como lugar de democratização de saber disciplinário. Nesta última modalidade, a mobilização de vários dispositivos expográficos, que permitem a interação, imersão, experimentação, busca atrair mais visitantes, que passam a serem vistos como consumidores ou usuários. O pressuposto, no entanto, é de que o Museu deve cumprir a missão de educar o público, diminuindo um déficit de conhecimento. Em uma relação de comunicação unidirecional, curadores e especialistas, considerados como únicos detentores de conhecimento, se encarregam de transmiti-lo para o público passivo e desinformado. Ao se referir à versão pós-moderna desse tipo de museu, Padró analisa que, a despeito de uma suposta inovação expositiva, com introdução de cenografias, imagens, manequins "se sigue fomentando uma concepcción académica, didáctica y elitista de los contenidos que se seleccionan para "hacerse" públicos (...)" ( Padró, 2003: $56)^{5}$.

Grande parte dos museus universitários, como de resto os demais museus, conforma-se entre o primeiro e segundo modelo de comunicação expositiva; informações científicas e culturais são disponibilizadas e/ou disseminadas, com pretensões de se diminuir uma carência de conhecimento, por meio de linguagens e recursos mais ou menos acessíveis ao público. Este cenário, no entanto, vem se alterando, em um debate incrementado desde os anos de 1980 e 1990 pelo campo museal, em todo mundo, mas também, no caso dos museus universitários, por mudanças específicas e mais recentes na universidade pública brasileira.

Nas duas últimas décadas, a intensificação do processo de democratização da universidade pública brasileira tem reverberações notórias nas políticas culturais e extencionistas, aí compreendidos os museus e as coleções universitárias. Como lembra Fonseca (20l8), a universidade no Brasil, ainda que com predomínio das instituições públicas, percorreu uma trajetória elitista desde a sua criação, no início do século $X X$. Destinou-se historicamente a segmentos minoritários da população, compostos por brancos das classes médias e abastadas da sociedade. A partir dos anos 2000 esse quadro começa a ser alterado, com a adoção de uma política educacional pautada na inclusão social, que promove a expansão de estruturas e vagas universitárias, estabelecimento de cotas sociais e raciais, financiamento de estudantes, dentre outras iniciativas.

5 Se segue fomentando uma concepção acadêmica, didática e elitista dos conteúdos que se selecionam para torna-los públicos (...)" (tradução nossa). 
Como resultados imediatos dessa política, observa-se uma mudança substancial do perfil da comunidade acadêmica e a ampliação das relações das instituições universitárias com a sociedade. No que concerne aos museus, tais mudanças certamente repercutem nos processos de formulação de uma agenda democrática, em estreito diálogo, também, com preceitos que, há mais de 30 anos, consolidam o pensamento e a prática museológica em direção a uma perspectiva social. A confluência desses fatores foi decisiva para colocar na ordem do dia dessas instituições questões como o direito da sociedade ao patrimônio universitário, o reconhecimento da legitimidade de outros saberes para além do conhecimento acadêmico e a necessidade de se romper com o modelo do déficit informacional na comunicação museal.

Todos esses desafios podem ser sintetizados pelo movimento de deslocamento do museu do lugar de afirmação e expansão de saberes disciplinares para o de lugar democrático de saberes. Uma nova forma de comunicação com o público é delineada, tendo como pressuposto de que o museu é lugar da dúvida, da controvérsia, da apresentação de múltiplas visões e da negociação de interpretações e significados, conforme assinalado por Padró (2003). Essa modalidade guarda correspondência com o que Davallon (2010 e 20II) identifica como Museologia do ponto de vista. Derivada do espetáculo, nessa terceira categoria postulada pelo autor prevalece a ideia da imersão do sujeito no espaço da exposição. O objeto e o saber perdem primazia, em favor da experiência sensorial, sensitiva e subjetiva do sujeito, o qual é compreendido como uma espécie de ator da cena expositiva, cujas interpretações concorrem para a produção de sentidos. Embora a abordagem de Davallon não se alinhe exatamente com a de autores, como Padró, que enfatizam uma museologia que interpela discursos e representações sociais, uma e outra vertente concordam que a autoridade do museu e a hegemonia de seus enunciados são desafiados pela perspectiva e experiência do visitante.

\section{O que pode a comunicação em museus universitários}

A passagem da comunicação apoiada na transmissão para o modelo que pressupõe negociação representa uma guinada significativa da concepção que se tem do visitante. São exemplos consagrados desse processo os museus surgidos em contextos patrimoniais comunitários, étnicos, territoriais, fundamentados pelas reflexões da Nova Museologia ou da Sociomuseologia. Mas os exemplos não se limitam a essas experiências. É importante reconhecer movimentos nessa direção também nos museus de perfil tradicional. Práticas educativas, exposições temporárias, programas culturais ou pequenas intervenções em exposições de longa duração criam fissuras nas narrativas museais, abrindo canais de interlocução com o visitante. Em outras palavras, a diversidade de linguagens, recursos, e das formas de mediação e interação não se dá apenas de museus para museus, mas está presente também em um mesmo museu. Esse é o caso de muitas instituições museológicas universitárias, sobretudo daquelas que surgiram estreitamente associados às demandas acadêmicas, e que não tinham, pelo menos em sua origem, o público como principal foco de atuação.

Neste cenário, vale analisar algumas perspectivas que apresentam potencial comunicacional em museus universitários: a exposição de controvérsias históricas, sociais e científicas, a exposição dos processos de produção de conhecimento e as possibilidades de se dar acesso a coleções, pouco conhecidas ou acessíveis. 
O tema das controvérsias não é novo. Desde os anos de $1990^{6}$ tem mobilizado um debate no campo museal, conduzido pela aposta em uma comunicação que possibilite engajar o visitante, provocando-o a tomar posições e a coproduzir sentido em suas experiências no museu.

Convém compreender o que vem a ser controvérsia. Ao analisarem as abordagens de teóricos sobre o termo, Predretti e lannini (2020) admitem que o termo é complexo e fluido. Envolve conflitos de discursos, disputas de significados, tendo em vista as diferenças de normas socioculturais, religião, valores, em sociedades democráticas e plurais. Também está associado ao que traz inquietações, incertezas e ambiguidades. E nessa direção, diz respeito às inquietações pessoais do visitante ou do museu ou aquelas decorrentes da prática de produção de conhecimento - dúvidas, resultados inclusivos, contradições, etc. Em outras palavras, controvérsia é tanto a base, o ponto de partida para construção do conhecimento, como também se refere a questões que desafiam práticas sociais e mobiliza atores sociais. Em uma ou outra vertente, ao abraçar a perspectiva da controvérsia e da negociação, os museus se comprometem a um só tempo engajar criticamente os visitantes em questões da ciência e de suas condições de produção, quanto a acolher os conflitos que atravessam qualquer sociedade.

Adotar essa perspectiva implica abandonar uma postura comum a grande parte das exposições, como lembram Girault e Molinatti (20II), na qual os museus reivindicam para si a neutralidade, tanto quanto reiteram o mito da neutralidade e objetividade do conhecimento. Além expor problemáticas controversas, a exemplo de temas da biologização de questões sociais, desenvolvimento sustentável ou passados difíceis, os museus devem reconhecer diferentes formas de conhecimento, e debater a própria natureza da ciência como algo que não é estático, fixado em verdades imperturbáveis, mas que se inscreve no seu tempo, no fluxo do mundo social. Como sugerem os autores, os museus tanto podem ocupar o lugar de atores no debate público ou, de organizadores e/ou testemunhos desse debate.

Outra forma de envolvimento da sociedade nos museus seriam as curadorias colaborativas, ou como assinalam Girault e Molinatti (20II) as coproduções, nas quais grupos da sociedade participam diretamente no desenvolvimento do conhecimento e das exposições que lhes dizem respeito. A ideia de negociação aparece então como referência importante, como uma dimensão comunicacional contemporânea dos museus que “(...) est bien au coeur de la 'négociation' entre l'intention des programmateurs et la réalité du comportement des spectateurs" (Wolton, 201 I: 197) 2 .

Como um desdobramento da negociação está o próprio debate a respeito da decolonização e democratização dos museus, que problematizam as circunstâncias de criação dessas instituições, a proveniências de suas coleções e as narrativas que sustentam. A alternativa colaborativa permite que novos sujeitos venham à cena museal e que hierarquias de curadorias e saberes sejam rompidas, em favor de populações e grupos sociais silenciados, submetidos a relações opressivas, que passam eles próprios a contar suas histórias nos museus ${ }^{8}$.

6 A respeito da abordagem do tema na bibliografia ver Navas; Contier; Marandino (2007).

7 “(...) está no centro da negociação entre a intenção dos programadores e a realidade do comportamento do espectador" ( tradução nossa).

8 Dentre os vários autores tratam desses processos, ver Golding (2013). 
Neste cenário desafiante, parece ser produtivo pensar que os museus universitários podem assumir papel protagonista em processos controversos e de negociação, considerando suas especificidades. Vale lembrar que o princípio da autonomia universitária, que garante a essas instituições independência em relação ao Estado e ao governo, assegura a liberdade de pensamento a todos os setores e segmentos da universidade, incluindo os seus museus. Ora, a liberdade pedagógica e de pesquisa permite aos museus universitários, e talvez mais que quaisquer outros, reunirem condições particularmente oportunas à experimentação em exposições de questões que podem desafiar valores socioculturais, visões dominantes da ciência, da história ou da cultura, ou mesmo contrariar interesses de determinados grupos sociais.

Da mesma maneira, os museus universitários são lugares privilegiados para se mostrar a ciência em ação. Mais que mostrar os resultados bem sucedidos do conhecimento construído é particularmente promissor que promovam a comunicação pública da pesquisa, ao expor as condições, os ambientes e as dinâmicas implicadas na produção do conhecimento, focalizando os métodos empregados (Wagensberg, 2005; Morgan, 20I I).

Ao argumentar a respeito de novos dispositivos expositivos que se prestem a esse propósito, Morgan (20II) menciona a experiência do laboratório em atividade, que funciona também como vitrine, instalado no "Deutsches Museum" em Munique, e que está franqueado ao olhar ou mesmo à interação com visitante do museu. Esse ou outro expediente que tenha o mesmo objetivo contribui para romper com mitos em relação à produção do conhecimento, porque torna acessível o cotidiano do fazer ciência, os sujeitos envolvidos, os objetos que os cercam, os procedimentos e as experimentações e, inclusive, resultados nem sempre bem sucedidos.

Nota-se que em todo o mundo, as universidades concentram, hoje, significativa infraestrutura de pesquisa. Os museus universitários podem desempenhar papel chave na extroversão desse patrimônio, que diz respeito a toda a sociedade, buscando alternativas que conciliem o acesso público às demandas de desenvolvimento dos projetos de investigação. O “laboratório de vidro", mencionado por Morgan é uma delas. Outro caminho, talvez mais ao alcance da realidade das universidades brasileiras, seja uma atuação descentralizada dos museus nos campi, conduzida por programas em parceria com laboratórios, ateliês, herbários, etc., de comunicação da ciência e da pesquisa.

Além da exposição de controvérsias e de processos de produção de conhecimento, a comunicação em museus universitários pode ganhar potência ao ampliar as possibilidades de acesso aos acervos universitários, muitos dos quais se encontram em reservas técnicas, laboratórios, arquivos ou dispersos em departamentos e dificilmente chegam a ser exibidos para o público. Como já mencionado, o patrimônio científico e cultural da universidade apresenta expressiva diversidade tipológica, à qual corresponde ao amplo leque de saberes que tem abrigo na instituição. Ao observar que as disciplinas existem graças a instituições de ensino e pesquisa,Wagensberg (2005) afirma que o museu de ciência, e aqui se pode aplicar aos museus universitários, pode lidar com qualquer tipo de realidade e conhecimento, da física à biologia da literatura ao urbanismo.

Se é fato que os museus universitários podem tratar de variadas realidades, o mesmo não acontece em relação às possibilidades de expor em seus espaços o vasto patrimônio acumulado pelas universidades. As tecnologias de informação e comunicação não apenas têm otimizado a disponibilização de in- 
formações e permitido criar ambientes de imersão ou experimentação em exposições, como podem ser importantes aliadas na extroversão, por meio digital, de acervos pouco acessíveis.

Um exemplo são as obras de arte, geralmente dispersas pelos campi universitários, sob a tutela administrativa de distintas unidades que, reunidas e disponibilizadas em catálogos virtuais, ganham visibilidade, são ressignificadas e se institucionalizam?. Da mesma maneira, coleções em uso para ensino ou pesquisa ou cujas condições de conservação desaconselham sua exposição podem adquirir ressonância e alcançar novos públicos, legitimando seu estatuto patrimonial.

A reunião e a disponibilização de acervos em meio digital, particularmente na Web, criam um novo patamar nas relações que os museus universitários constroem entre o público e o patrimônio. $O$ uso da tecnologia, orientado por propósitos fundamentados do ponto de vista museológico, além de ampliar e formar novos públicos do patrimônio da universidade, pode favorecer diálogos interdisciplinares na abordagem de coleções de naturezas distintas; reinserir acervos, antes abandonados ou pouco conhecidos, em ciclos virtuosos de pesquisa e ensino; encorajar a formação de redes de pesquisas congregando distintas instituições e ensejar redes de acervos tanto quanto empréstimos e circulação física de coleções entre museus.

\section{Conclusão}

Do museu organizado para atender às demandas de sábios e eruditos ao museu tornado um meio de comunicação, essas instituições fizeram um percurso no tempo em direção ao espaço público, ao visitante. E de lugar de instrução pública a espaço de aprendizagem recíproca entre os sujeitos, a comunicação no museu se deslocou do modelo hierárquico, que pressupõe uma carência de informação do receptor, para uma comunicação complexa e multireferenciada, construída pela polissemia de vozes. O museu perde a aura de autoridade incontestável; perde a primazia como único agente de construção de seus enunciados, para se tornar lugar de ressonância de pontos de vista de distintos de atores sociais, de distintas narrativas e formas de conhecimento.

Mais que instituição, os museus devem ser compreendidos como práticas socialmente significativas, como sublinha Padró (2003). Como lugares que promovem interpretações da realidade, eles conformam responsabilidade pública, porque engendram a consciência, compartilham conhecimentos, disseminam ideias e valores, ou mesmo mitos e estereótipos. As mudanças que os museus operam em suas práticas de comunicação, nos sistemas de linguagem de suas exposições e nas formas como engajam o público, os projetam em uma nova dimensão politica, no quadro dos sistemas da cultura e ciência.

Neste cenário, os museus universitários podem figurar como conectores que quebram o isolamento da ciência, contribuindo para estreitar a relação da universidade com sociedade. A exposição do que se conhece e, sobretudo, como se conhece, da provisoriedade de verdades e do contraditório, dos processos expositivos colaborativos e interativos, todas essas possibilidades credenciam os museus universitários a assumirem um papel de destaque na formação da opinião pública em ciência, como postula Wagensberg (2005). Desdobram ainda desse desafio a tarefa de publicizar as implicações éticas, sociais 
O Desafio da Comunicação nos Museus Universitários

e políticas do conhecimento e promover negociações para o reconhecimento da legitimidade de controvérsias. Diante do avanço de pensamentos avessos à ciência, o alinhamento dos museus universitários em defesa do conhecimento, da universidade e do seu patrimônio científico e cultural significa apostar nas relações democráticas na sociedade brasileira.

\section{Referências}

BRULON, Bruno. Entendendo a Musealização como conceito social: entre o dar e o guardar. In: MENDONÇA, Elizabete de Castro (org). Museologia, Musealização e Coleções: conexões para reflexão sobre o patrimônio. Rio de Janeiro: UNIRIO/Escola de Museologia: Secretaria Municipal de Cultura/Ecomuseu do Quarteirão Cultural do Matadouro de Santa Cruz, 2016. p.38-54.

DAVALLON, Jean. Comunicação e sociedade: pensar a concepção da exposição. In: BENCHERIT, Sarah Fassa; BEZERRA, Rafael Zamorano; MAGALHÃES, Aline Montenegro (Org.). Museus e comunicação: exposições como objeto de estudo. Rio de Janeiro: Museu Histórico Nacional, 20 I0. p. 2 I-34.

.Le Pouvoir Sémiotique de l'espace. Hermés, La Revue.C.N.R.S

Editions. 20I I/3 nº, p. 38-64.

DESVALLÉES, André; MAIRESSE, François (Dir.) Muséalisation. In: Dictionnaire Encyclopédique de Muséologie. Paris:Armand Colin, 20I I. p. 25I-269.

FONSECA, Marcelo. Democracia e acesso à universidade no Brasil: um balanço da história recente (1995-20 I7). Educar em Revista. Curitiba, Brasil, v. 34, n. 7I, p. 299-307, set./out. 2018.

JULIÃO, Letícia. Museus e coleções universitárias. In.: NASCIMENTO, Adalson; MORENO, Andrea (org.). Universidade, memória e patrimônio. Belo Horizonte: Mazza Edições, 2015. pp. I4-24.

LATOUR, Bruno. Redes que a razão desconhece: laboratórios, bibliotecas, coleções. In: BARATIN, Marc; JACOB, Christian (Dir.). O poder da biblioteca. 3. ed. Rio de Janeiro: Ed. UFRJ, 2008. p. 2 I-44.

LORENTE, Jesús-Pedro (diretor);ALMAZÁN, David (coordenador). Museología Crítica y Arte Contemporáneo. Zaragoza: Prensas Universitarias de Zaragoza, 2003.

LOURENÇO, Marta; GRANATO, Marcus. Thesaurus de Acervos Científicos em Língua Portuguesa. Página inicial. Disponivel em: http://thesaurusonline.museus.ul.pt/ default.aspx.Acesso em: 3 de junho de 2020.

MEYER, Morgan; SCHUBLER, Peter. Le Laboratoire "en ventre": exposer la science en action au musée. Hermés, La Revue. C.N.R.S Editions. 20I I/3 6I, p. 185-187 
NAVAS, A. M., CONTIER, D., MARANDINO, M.. Controvérsia científica, comunicação pública da ciência e museus no bojo do movimento CTS. Ciência \& Ensino. São Paulo. 2007. (Online)., v. I, I-I 2

PANISSET, Ana; JULIAO, Letícia . Acervo Artístico da UFMG: O papel da Museologia na gestão do patrimônio universitário. In: III SEBRAMUS, 20I7, Belém. Museologia e suas interfaces críticas: museu, sociedade e os patrimônios, 2017. v. I. p. |893-19|I.

PEDRETTI, Erminia ; IANNINI, Ana Maria Navas. Engaging controversy. In: Controversy in Science Museums: re-imagining exhibition spaces and parctices. Londres: Nova York: 2020.

RASSE, Paul; GIRAULT, Yves. Regard sur les arts, les sciences et les cultures en mouvement, à travers les débats qui agitent líntituition muséale. Hermés, La Revue. C.N.R.S Editions. 201 I/3 6I, p. II-I6.

SCHIELE, Bernard. L'invention simultanée du visiteur et de l'exposition. In: Publics et Musées, $\mathrm{n}^{\circ} 2$, 1992. Regards sur l'évolution des musées (sous la direction de Jean Davallon) pp. 7I-98; doi : https://doi.org/I0.3406/pumus.1992.1016 https://www.persee.fr/doc/pumus_II64-5385_1992_num_2_I_I016.Acesso em 06/06/2020

SEGANTINI,Verona Campos ; JULIÃO, Letícia. A UFMG e o patrimônio da ciência e cultura: da obsolência à musealização. In: GRANATO, M. RIBEIRO, E. S.; ARAUJO, B. M. (Org.). Cadernos do Patrimônio da Ciência e Tecnologia: instituições, trajetórias e valores. I ed.Rio de Janeiro: MAST, 20 I7, v. I, p. I I I-I 29.

WAGENSBERG, Jorge. The "total" museum, a tool for social change. História, Ciências, Saúde - Manguinhos. Rio de Janeiro. v. I 2 (suplemento). p. 309-32 I, 2005.

WOLTON, Dominique. Les Musées. Trois Questions. Hermés, La Revue. C.N.R.S Editions. 201 I/3 n 61 , p. 195-199 